\title{
O DISCURSO POLÍTICO E O CORPO NA TELEVISÃO: DEBATE/COMBATE
}

\author{
Luciana Carmona Garcia Manzano* \\ Universidade de Franca \\ Franca, SP, BR
}

\section{Resumo}

Este artigo busca analisar o discurso político eleitoral a partir dos sentidos inscritos sobre o corpo dos candidatos à presidência na campanha de 2014 durante a transmissão televisiva do último debate veiculado pela Rede Globo de Televisão, no dia 24 de outubro. A partir do eixo teórico dos estudos do discurso e dos estudos antropológicos sobre a produção imagética na história social das civilizações, o texto objetiva refletir sobre o funcionamento do discurso político atual inscrito na dinâmica do posicionamento corporal dos candidatos na produção/transmissão televisiva que configura o gênero debate.

Palavras-chave: Análise do discurso; corpo; discurso político; televisão.

\section{POLITICAL DISCOURSE AND THE BODY ON TELEVISION: DEBATE/FIGHTING}

\begin{abstract}
This article seeks to analyze the electoral political discourse from senses inscribed on the body of the presidential candidates in the 2014 campaign during the television broadcast of the last debate aired by Globo TV, on 24 October. Based on theories of discourse studies and anthropological studies of imagery production in the social history of civilizations, the paper aims to think over the functioning of the current political discourse inscribed in the dynamics of the body position of the candidates in television production/broadcast that characterizes the political debate genre.
\end{abstract}

Keywords: Discourse Analysis; body; political discourse; television.

\section{Introdução}

Este artigo é fruto de pesquisa no campo da Análise do Discurso, a partir da observação sobre o funcionamento do discurso político na televisão - temática à qual venho me dedicando desde 2007, por ocasião do mestrado e do doutorado e, atualmente, como docente e orientadora de trabalhos nessa linha de pesquisa. Particularmente, para o desenvolvimento deste texto, parto da inquietação causada pelo clima de ódio instaurado na campanha presidencial de 2014, sobretudo no segundo turno, quando se amplia a circulação de discursos agres- sivos entre eleitores simpatizantes de um ou de outro candidato, a saber: Aécio Neves e Dilma Rousseff.1

A circulação desses discursos é observada, especialmente, nas redes sociais, mas também acaba perpassando as práticas discursivas que circularam na televisão, tanto nos programas dos candidatos durante a transmissão do Horário Gratuito de Propaganda Eleitoral quanto nos debates promovidos pelas redes abertas de televisão. Dessa forma, ao alcançar o meio televisivo, o corpo é coagido pela própria configuração do enquadramento do cenário e faz circular efeitos de sentido que se inscrevem sobre sua superfície.

\footnotetext{
* Docente permanente do Programa de Pós-Graduação em Linguística da Universidade de Franca (UNIFRAN) na linha de pesquisa do discurso. Desenvolve pesquisas na área de Teoria e Análise Linguística, com ênfase em Análise do Discurso, atuando principalmente nos seguintes temas: semiologia histórica, discurso político, televisão, mídia, contemporaneidade. Atua como docente nas áreas de Linguística Geral, Teoria e Análise Linguística, Língua Portuguesa, Didática. Email: lcgmanzano@gmail.com.
} 
Neste texto, trago como material de análise trechos do último debate televisivo entre os candidatos Dilma Rousseff e Aécio Neves, transmitido pela Rede Globo de Televisão no dia 24 de outubro de 2014 . $^{2}$

\section{Análise do discurso, discurso político e a ordem do olhar na televisão}

As reflexões teóricas que embasam este artigo se constituem na esteira das reflexões de Jean-Jacques Courtine, sobre o discurso político contemporâneo e sobre os estudos do corpo nas ciências sociais, que perpassam desde conceitos da Análise do Discurso (AD) engendrada por Michel Pêcheux, postulados de Hans Belting sobre a antropologia das imagens no seio social, até as reflexões de Michel Foucault sobre as práticas sociais a partir das quais se podem observar sentidos inscritos no(s) corpo(s).

Os construtos teóricos da Análise do Discurso alicerçam nossas reflexões na medida em que Pêcheux (1997) define, ainda no início do desenvolvimento da $\mathrm{AD}$, que o discurso se encontra no entrelaçamento do fio da história com o fio da língua, no sentido de que, para tomar como objeto de estudo o discurso e compreender seus efeitos de sentido, é impreterível pensar a historicidade que circunscreve a materialidade do objeto. Ainda segundo o autor, o discurso é apreendido na relação entre a materialidade linguística e a ideologia manifestada por meio da linguagem.

Posteriormente, Pêcheux (1999) passa a considerar a imagem também uma materialidade discursiva no campo da $\mathrm{AD}$ por compreendê-la como dispositivo operador de uma memória social, pois ela comporta, em seu interior "um programa de leitura, um percurso escrito discursivamente em outro lugar (PÊCHEUX, 1999, p. 51)".

É possível compreender, neste momento das reflexões de Pêcheux, uma herança ainda calcada na linguística como materialidade da linguagem, mas já é possível observar as instâncias da historicidade e da discursividade inscritas na materialidade da imagem. Essas instâncias, consideradas também por Courtine (2009), dão lugar a outro modo de observar a materialidade da imagem a partir de seu funcionamento social: ela não comporta em si um modelo de língua. Ainda que possam ser encontrados indícios e traços do surgimento de um sentido, não se encontram propriamente os signos linguísticos. A imagem significa a partir da (re) atualização dos sentidos inscritos em uma memória visual: os sentidos da imagem circulam a partir de práticas sociais reconhecidas na sua materialidade.

Assim, se há um reconhecimento imagético de uma prática social, haverá sempre uma memória visual a partir da qual circulam os sentidos de imagens inscritas em determinada cultura social, ou seja, haverá sempre um "já visto" ao qual as imagens remetem. A partir dessa reflexão, Courtine passa a considerar a existência de uma intericonicidade: noção que orienta a compreensão sobre a construção histórica dos sentidos em uma cultura por meio de uma genealogia dos indícios encontrados nas imagens em circulação.

A intericonicidade instaura uma correlação entre imagens ditas "externas" e "internas". Por "imagens externas" podemos compreender aquelas materializadas social e coletivamente em um meio de circulação ou, ainda, compreendê-las como a possibilidade de uma imagem inscrever-se em uma série de imagens, à esteira do que Foucault (2000) postula sobre a rede de formulações à qual pertence o enunciado: assim, haveria uma rede de imagens que comporia um "já visto" em relação a uma nova produção imagética, considerada como uma materialização de sentidos. Já como "imagens internas", compreende-se o que é visualmente internalizado pelo indivíduo em forma de lembranças, recordações ou impressões visuais - que podem fazê-lo observar, de modo distinto a outro indivíduo, indícios de uma determinada imagem.

Por considerar a possibilidade de observação dos sentidos que podem ser percebidos na parte visível do corpo, já que essa possibilidade é a consequência da condição do homem enquanto ser simbólico e social, a noção de intericonicidade busca identificar, na materialidade imagética, índices deixados por imagens anteriores, a fim de reconstruir uma genealogia do que produz sentido no campo do olhar, em um certo momento histórico, em uma determinada cultura. Desse modo, toda imagem faz ressurgir outras imagens, ou ainda, dito de outro modo, toda imagem contém em si indícios, ves- 
tígios, sinais, deixados por outras imagens que circularam antes e em outro lugar. A partir da busca por esses indícios trazidos da relação intrínseca das imagens, é possível chegar ao sentido icônico das representações imagéticas em uma cultura.

Ao observar o discurso político televisivo como objeto de estudo a partir da teoria da $\mathrm{AD}$, compreendese a transmissão dos blocos de sentido como um conjunto enunciativo: é a partir desse conjunto enunciativo que se instauram as sequências de análise na qual incidem o verbo, a imagem e o som. Nesse conjunto, o corpo adquire uma visibilidade ampliada pelo enquadramento da câmera de televisão, e passa a ser o ponto de ancoragem do discurso político televisivo (COULOMB-GULLY, 2003).

$\mathrm{O}$ enunciado televisivo, então, se materializa no sincretismo entre a língua e a imagem. Entendida como discurso, essa materialidade que congrega as linguagens verbal e visual se entrecruza com o fio da história e instaura, para o analista, uma instância do olhar que produz outros sentidos. Trata-se de um discurso que é lido e visto ao mesmo tempo, no qual se encontra uma ordem do olhar. O olhar é necessário e indispensável na instituição do meio televisivo como transmissor do discurso político; e é pela imagem que ele se realiza.

Belting (2004) analisa a produção social das imagens ao longo da história cultural da humanidade a partir de uma relação com o meio de circulação em que ela se instaura e o olhar/corpo, no sentido de que o olhar mantém uma intensa relação com o corpo que olha e com o meio de circulação para o qual incide esse olhar. Do mesmo modo, o corpo humano está diretamente envolvido na produção de imagens, porque ele também se constitui um "meio" no qual se formam as imagens interiores (mencionadas também por Courtine (2009) e supracitadas neste texto), de modo que uma imagem sempre será o resultado de uma simbolização pessoal ou social. Essa relação antropológica do funcionamento social da imagem analisada por Belting contribui para a abordagem discursiva da imagem em funcionamento no discurso político televisivo, pois também a coloca dentro de uma relação da materialidade do objeto com o fio da história.

Courtine (2006), em seus trabalhos sobre as transformações da configuração do discurso político con- temporâneo, define-o como uma construção enunciativa sobre a qual incide um caráter performático e que está submetida às exigências do meio audiovisual, já que se compõe de um tipo de colagem ou justaposição de falas com práticas gestuais e expressões corporais e faciais. Assim, é pela característica visual que a televisão se diferencia de outros meios de transmissão/circulação de discursos e, nesse sentido, o olhar é atraído para a construção dos sentidos.
(...) o texto político foi trabalhado por partes no interior de novas práticas de escrita e leitu- ra: produziu e recebeu novas formas, diálogos, entrevistas, holofotes de televisão, videoclipes políticos. Leem-se menos frequentemente as páginas impressas de um jornal ou livro do que se ouve ou se vê em uma tela. De agora em dian- te, o discurso político não pode ser dissociado da produção e recepção de imagens da mesma maneira que o discurso do homem político não poderia mais se separar de sua imagem. O mo- delo do porta-voz político mudou profunda- mente os modos de subjetivação, regulados por novas práticas. (COURTINE, 2006, p. 84-85)

A condição de recepção discursiva possibilitada pela televisão - que coage o olhar para um determinado tipo de observação dessas imagens - se constrói socioculturalmente por duas razões: uma delas é a estrutura física e técnica que possibilita a aparição dinâmica da imagem, ou seja, o corpo em movimento; a outra está calcada num percurso histórico que promove condições de possibilidade para que determinada(s) imagem(ns) circule $(\mathrm{m})$ e produza $(\mathrm{m})$ efeitos de sentido. A transmissão de imagens em movimento reproduz um tempo presente em andamento que confere à imagem uma maior ilusão de autenticidade, além de uma ilusão de transparência, de verdade. ${ }^{3}$ É nessas condições de possibilidade que a imagem se constrói e instaura um modo de comportamento visual que submete o olhar a uma determinada ordem para produzir sentidos. As dimensões físicas do aparelho televisivo e sua instalação no mobiliário incidem, também, sobre o corpo do espectador, que deve se posicionar, preferencialmente, sentado para a recepção da transmissão: assim, sob a ilusão de uma experiência confortável, o corpo é coagido a um modo de ver que participa da produção de sentidos. 


\section{O corpo e os sentidos nas ciências humanas}

Uma das grandes contribuições das ciências humanas com relação aos estudos sobre o corpo deve-se à relação entre corpo e sujeito: desloca-se a compreensão anatômica, derivada da ciência médica, de que o corpo é o depositário de sinais visíveis de saúde ou de doença, para a investigação sobre como o corpo emite e deixa sinais de construções ideológicas em uma determinada cultura. A prática é antiga, mas os estudos sobre o corpo do sujeito são, de certo modo, recentes.

À esteira do que postula, ainda, Courtine (2013) sobre os estudos do corpo nas ciências humanas, compreendemos que Foucault tem uma produção expressiva no que diz respeito à inserção do corpo no discurso das ciências da humanidade, que pode ser observada em trabalhos como Vigiar e Punir, História da Sexualidade e História da loucura. Trata-se de um olhar bastante cuidadoso, na longa duração no tempo histórico, sobre o modo como o poder se inscreve e incide sobre o corpo do sujeito, desde o exterior quando analisa o olhar panóptico daquele que vigia os corpos do sistema prisional - até o que passa a ser interiorizado pelo sujeito - quando localiza micropoderes que agem como técnicas e controle de si sobre as condutas e comportamentos do sujeito.

A partir dos jogos de verdade inseridos nas relações de poder, o corpo é coagido a conduzir-se de modo tal que se inscreva sob um regime ético e moral, e é por meio dessa coerção que se constitui sujeito. $\mathrm{O}$ jogo de verdade instituído pelo poder eclesiástico do cristianismo, por exemplo, estabeleceu, historicamente, uma conduta corporal do sujeito que compreende o ato sexual como uma prática associada ao mal e ao pecado.

Ao observar o corpo humano sob o viés da Antropologia, podemos compreender, de acordo com as reflexões de Belting (2004), que o corpo humano sempre constituiu um dos grandes símbolos imagéticos ao longo das culturas humanas, tanto nas sociedades orientais quanto ocidentais.

Desde a Antiguidade, as estátuas que homenageavam indivíduos mortos em um grupo social ou religioso eram esculpidas na forma do próprio corpo do sujeito morto. Simbolicamente, imagem de uma eternidade, lembrança viva do legado de seus valores morais, incorporação da identidade do sujeito entalhada na pedra.

Desse modo, é possível articular uma relação entre a simbologia do corpo enquanto materialidade viva e a da estátua: a estátua (ou mesmo a pintura) carregava em si o poder de simbolizar a vida porque podia incorporar a identidade do indivíduo desaparecido. O corpo, vivo, coloca em circulação os sentidos dessa identidade. Assim, é preciso olhar o corpo do homem político como meio de transmissão de um certo tipo de identidade, de uma identidade que se caracteriza como funcional - já que é uma identidade que se constrói a partir de sua aparição enquanto figura pública -, que evidencia e (re) atualiza discursos em uma época dada.

A simbolização do corpo como imagem no seio social também pode ser observada na instituição do cristianismo, que tem como símbolo e prova física de existência o corpo de Jesus Cristo: paradigma corporal de um sujeito virtuoso, imagem de um Deus encarnado; traz em si as características do mundano e do sagrado; foi eternizado como único corpo que venceu a morte (porque subiu aos céus em sua materialidade corporal).

Compreendendo que a imagem se constitui a partir de um meio de circulação, que pode, inclusive, recair sobre o próprio corpo do sujeito, esse corpo se torna um ícone e o que ele permite ver é uma simbolização de conceitos sociais. No caso do corpo de Jesus Cristo, não se vê o corpo como um material perecível e individual, mas como uma materialidade que simboliza a crença religiosa e fortalece o discurso religioso cristão. Do mesmo modo, pode-se trazer esta reflexão para observar os sentidos dados a ver a partir do corpo do indivíduo político tornado candidato, que se torna um corpo funcional definido por um momento histórico denominado campanha eleitoral. Esse corpo tornado imagem (por meio da transmissão televisiva, por exemplo) simboliza uma prática discursiva que o erige como sujeito político, carregado de simbolizações situadas no imaginário social de uma época.

\section{O corpo político e o debate televisivo}

É possível perceber, até aqui, que o corpo enquanto elemento simbólico atua num jogo de sentidos que en- 
tram em circulação a partir do meio de transmissão e do gênero discursivo pelo qual ele se faz imagem. Num programa partidário de campanha eleitoral que leva o nome do candidato como símbolo do início do programa, como acontece com a materialidade dos programas do Horário Gratuito de Propaganda Eleitoral (HGPE), o corpo do indivíduo político é alçado à condição de estrela do espetáculo, modo pelo qual os sentidos que emergem dessa transmissão buscarão revelar a virtuosidade e a capacidade do líder político de governar uma nação (MANZANO, 2014).

$\mathrm{O}$ que pretendemos mostrar a partir do objeto de estudo que selecionamos, a saber, o debate entre os candidatos, transmitido por uma rede aberta de televisão, é que, neste gênero, o meio de transmissão coage os corpos e produz outros sentidos para o mesmo momento de campanha eleitoral.

Para tratar deste item do texto, optamos por não lançar mão da captura das imagens que analisaremos; em vez disso, procederemos metodologicamente com a descrição e interpretação dos enunciados televisivos, de modo que as imagens que são parte desta análise serão referenciadas e o leitor está convidado a conferi-las a partir do link que dispusemos na primeira página do artigo.

Iniciaremos esta parte analítica do texto descrevendo o objeto de estudo: trata-se do último debate do segundo turno das eleições presidenciais, realizado e transmitido pela Rede Globo de Televisão, no dia 24 de outubro de 2014, a partir das 22 horas. O programa foi apresentado e mediado pelo jornalista Willian Bonner e contou com a presença de Dilma Rousseff e Aécio Neves, os dois candidatos ao segundo turno das eleições.

Comecemos pela descrição do cenário sobre o qual se desenvolveu o programa do gênero debate: no primeiro minuto do programa, quando se tem uma visão geral e dinâmica do estúdio por meio de imagens das várias câmeras posicionadas no entorno, é possível ver um cenário predominantemente azul, com um tablado redondo branco ao centro do estúdio, ao nível do solo. Fora do tablado, o apresentador em sua bancada de apresentação/mediação. Uma espécie de amurada - estrutura vertical - azul separa o espaço em que se posicionam candidatos e apresentador/mediador, dei- xando visualizar-se, a partir de uma tomada de cena aérea, uma grande área circular. O limite vertical da amurada estabelece o início do lugar em que se acomodam os espectadores, obedecendo essa estrutura circular e aumentando seu nível a cada fileira de assentos, como uma arquibancada.

Uma câmera está posicionada em determinado ponto da estrutura circular, de onde se pode observar uma bancada redonda, feita em material transparente, e, ao fundo da tela, uma área de projeção na qual se vê o logotipo do debate: Eleições 2014.

Outra câmera passa a transmitir a imagem frontal do apresentador/mediador situado atrás de sua bancada. Ele profere oralmente os dizeres: "Os eleitores aqui presentes participam de dois blocos do programa e a novidade que eu mencionei está nos outros dois blocos desse debate: o confronto direto entre os candidatos".

As expressões destacadas são pronunciadas com uma cadência mais marcada e são seguidas por um gesto da mão do apresentador/mediador que aponta dois dedos que sobem e descem acompanhando a pronúncia das sílabas tônicas.

Este gestual, em consonância com o pronunciamento oral do apresentador/mediador, marca visualmente - sobre a superfície do corpo do orador - o início de uma performance. Inserido no funcionamento do meio televisivo, que reproduz um presente em andamento, o conjunto enunciativo estabelece, na medida em que é dado a ver ao telespectador, um acontecimento discursivo ${ }^{4}$ o início de um combate.

Posteriormente, os dois candidatos se posicionam sobre a bancada central do tablado branco, de modo que o telespectador visualize o corpo dos candidatos situados frente a frente. Como a bancada é transparente, há uma ilusão visual de que os candidatos estão realmente em um enfrentamento sem obstáculos, cujo corpo participa de maneira global.

Posicionados frente a frente, os candidatos iniciam seus cumprimentos e turnos de fala, obedecendo a uma cordialidade esperada de sujeitos públicos (MANZANO, 2015); porém, a cada turno, o indivíduo que inicia sua fala adquire uma postura incisiva sobre a bancada: os dois candidatos, respectivamente, assumem uma postura pela qual se vê uma projeção corporal para 
frente (pé de apoio à frente do corpo, sugerindo uma investidura de ataque); de maneira semelhante, em seus turnos de silêncio, assumem uma postura a partir da qual se reconhece uma corporalidade defensiva (pé de apoio atrás do corpo, recuo do tronco).

Descritas as características do espaço cenográfico em que o programa é produzido e delineada a postura corporal dos participantes disso que se inscreve como "confronto direto" discursivamente pelo dizer do apresentador/mediador, é possível reconhecer indícios de outro espetáculo inscrito historicamente na cultura ocidental: as lutas entre gladiadores na arena do Coliseu romano. A alvenaria do que hoje é monumento histórico e turístico da Itália se assemelha à disposição cenográfica do debate: arena ao nível do solo, arquibancada crescente que se inicia após a delimitação circular determinada pela amurada ao redor da arena.

Ao reconhecer os indícios de uma luta de gladiadores na arena do Coliseu, também podemos observar indícios históricos da construção cultural do confronto como entretenimento social. A configuração do programa enquanto debate presidencial obviamente não promoverá o contato físico e/ou a investidura corpo a corpo com o adversário, mas a tensão discursiva promovida pelo jogo de indagações e respostas cronometradas, aliada à postura corporal de ataque/defesa, favorece a simulação de um combate que tem estatuto de entretenimento, pois se configura espetáculo e atinge o espectador/telespectador pela catarse.

O espetáculo que anuncia um confronto direto no debate se inscreve em um "já visto" histórico/cultural no qual a luta corporal se apresenta como um jogo: desse modo, cria-se a expectativa de um vencedor, de um herói. Os indícios desse jogo serão reconhecidos nas manchetes dos jornais dos dias seguintes, assim como na fala dos (tele)espectadores/eleitores: "fulano ganhou/perdeu o debate".

Guarinello (2007, p. 128) observa que os espaços nos quais se davam as lutas de gladiadores, os chamados anfiteatros (como o Coliseu) tinham um funcionamento social definido: simbolizavam a própria sociedade enquanto parte e reflexo da vida cotidiana. Nesse espaço, as lutas entre gladiadores, como espetáculo social, "ocupavam um lugar especial, ao mesmo tempo de honra e degradação". No debate presidencial, honra para o vencedor, degradação para o perdedor:

No caso particular dos gladiadores, sabe-se hoje que as classes dominantes tinham um envolvimento direto com sua realização não apenas financiando os jogos mas, muitas vezes, lutando como gladiadores na arena. Além disso, a historiografia moderna procura construir uma nova compreensão dos espetáculos no mundo romano - não apenas como momentos de diversão e prazer, mas como espaços de ação política, religiosa, cultural e identitária. (GUARINELLO, 2007, p. 127)

Observando os rastros deixados na história e os indícios suscitados no espetáculo televisivo do programa classificado como debate presidencial, também é possível reconhecer uma identidade cultural que se representa num espaço de confronto discursivo e simula um confronto corporal.

\section{Considerações finais}

De modo semelhante ao que tinha lugar nas arenas dos chamados anfiteatros, mas com todo o aparato tecnológico que configura o meio audiovisual como lugar de circulação de discursos, o espaço em que se constitui e desenvolve o debate entre os indivíduos políticos coage os corpos dos participantes a uma configuração que contém em si rastros de uma historicidade, incitando uma postura de combate corporal a um espaço de debate de ideias, promovendo um regozijo de outros corpos $\left(\right.$ os dos espectadores $^{5}$ ), pela representação do prazer da vitória. Os indícios históricos continuam corroborando um espaço de ação política a partir da arena de combate. O que está em jogo nessa performance do discurso político, a partir de um espetáculo visual que seduz o espectador e que (re)atualiza uma memória discursiva da luta política, é a busca pela adesão do potencial eleitor e da consolidação de uma vitória que transpassaria a arena do debate para o Palácio do Planalto.

Retornando às reflexões de Michel Foucault e Michel Pêcheux acerca das relações do discurso com a história, todo enunciado oferece um lugar à interpretação a partir do momento em que ele é tomado como 
uma série de pontos de deriva possíveis (PÊCHEUX, 1990). E essas derivas são possibilitadas pela existência do outro na história, que fazem irromper relações de interpretação e se organizam em uma memória social que continua produzindo sentidos. É de dentro desse olhar teórico que este artigo se constrói, observando as condições de possibilidades para que se compreenda o jogo político contemporâneo em sua configuração contemporânea, compreendendo o enunciado político como um conjunto enunciativo, do qual faz parte a materialidade verbal e visual.

(...) trata-se de compreender o enunciado na estreiteza e singularidade de sua situação; de determinar as condições de sua existência, de fixar seus limites da forma mais justa, de estabelecer suas correlações com outros enunciados a que pode estar ligado, de mostrar que outras formas de enunciação exclui. (FOUCAULT, 2000, p. 31)

A luta se configura em um jogo; o jogo é entretenimento. Trata-se de indícios de uma cultura visual que satisfaz o olhar e perpetua o espetáculo.

\section{Agradecimentos}

Agradeço a Ligia M. B. M. Araújo e Renata O. Carreon, doutorandas pelo Programa de Pós-Graduação em Linguística da UFSCar, pelas sugestões na confecção do artigo.

\section{Notas}

1. Este texto dialoga, em alguma medida, com o artigo "Corpos em combate: sentidos do (no) corpo em um debate presidencial televisivo", publicado na revista ARTEFACTUM, vol. 01/2015, no qual observo como a oralidade produz sentidos que negam os sentidos inscritos sobre o corpo. Neste artigo, ainda que eu trabalhe com o mesmo material de análise, busco observar a coação do corpo a partir do meio de circulação no qual ele é inserido.

2. O material de análise ainda pode ser acessado a partir do site G1, no seguinte endereço: http://g1.globo.com/ politica/eleicoes/2014/debate-presidencial-2-turno. html, acesso em 25 de maio de 2015.
3. Essa ilusão conferida à imagem da televisão vai ao encontro da necessidade do discurso político de produzir efeitos de verdade e o favorece em função de uma memória social que questiona sua legitimidade e o descredibiliza (a memória de que o político é sempre mentiroso e/ou corrupto).

4. A noção de acontecimento discursivo que abordo aqui é caudatária das reflexões de Michel Foucault, no sentido de que considerar um discurso como acontecimento significa tomá-lo na sua irrupção, sem pretender buscar origens, e no sentido de que ele instaura a interpretação e constrói uma verdade. Dessa forma, dentro do funcionamento da transmissão televisiva ao vivo, temos a construção incessante de um presente em andamento que toma corpo a partir da conjunção dos dizeres e gestos do apresentador. É num movimento discursivo que se constrói o acontecimento: o combate só se torna acontecimento a partir da prática discursiva do apresentador.

5. O leitor poderá conferir, a partir do registro audiovisual do debate, disponível no site G1 e citado neste artigo, que, em determinado momento do primeiro bloco do debate, o candidato Aécio Neves profere um dizer que desqualifica a candidata Dilma Rousseff e, imediatamente, a plateia reage com expressões orais de apoio, como uma torcida ao comemorar um golpe bem desferido no adversário.

\section{Referências}

BELTING, H. Pour une anthropologie des images. Traduit de l'allemand par Jean Torrent. Paris: Éditions Gallimard, 2004.

COULOMB-GULLY, M. Réthorique télevisuelle et esthétisation politique: le corps (en) politique. In: BONNAFOUS, S. et al. (Dir.) Argumentation et discours politique. Rennes: Press Universitaires de Rennes, 2003. p. 121- 130.

COURTINE, J-J. Metamorfoses do discurso político: derivas da fala pública. São Carlos: Claraluz, 2006.

Discursos sólidos, discursos líquidos: a mutação das discursividades contemporâneas. In: SARGENTINI, V., GREGOLIN, M. R. (Org.). Análise do Discurso: heranças, métodos e objetos. São Carlos: Claraluz, 2009. p. 11-20.

Decifrar o corpo: pensar com Foucault. Tradução de Francisco Morás. Petrópolis, RJ: Vozes, 2013.

FOUCAULT, M. História da loucura. São Paulo: Perspectiva, 1978

História da sexualidade I: a vontade de saber. Tradução de Maria Thereza da Costa Albuquerque e 
J. A. Guilhon Albuquerque. Rio de Janeiro: Edições Graal, 1988.

Arqueologia do saber. Tradução de Luiz Felipe Baeta Neves. Rio de Janeiro: Forense Universitária, 2000.

Vigiar e punir. Petrópolis: Vozes, 2004.

GUARINELLO, N. L. Violência como espetáculo: o pão, o sangue e o circo. História. São Paulo: vol. 26, n. 1, p. 125-132, 2007.

MANZANO, L. C. G. A ordem do olhar: sentidos da imagem no discurso político televisivo brasileiro. 2014. $216 \mathrm{f}$. Tese (Doutorado em Linguística) - Programa de Pós-Graduação em Linguística, Universidade Federal de São Carlos, São Carlos, 2014.

Corpos em combate: sentidos do (no) corpo em um debate presidencial televisivo. Artefactum. vol 1. P. 1-12. Rio de Janeiro: FAETEC, 2015.

PÊCHEUX, M. O discurso: estrutura ou acontecimento. Tradução de Eni P. Orlandi. Campinas: Pontes, 1990.

Semântica e discurso: uma crítica à afirmação do óbvio. $3^{\circ}$ edição. Tradução de Eni Puccinelli Orlandi et al. Campinas, SP: Editora da Unicamp, 1997.

O papel da memória. In.: ACHARD, P. et al. Papel da memória. Campinas: Pontes, 1999. p. 49-58.

Recebido em: 01/06/2015

Aceito em: 31/07/2015 